\title{
Recurrent TET2 mutations in adult T cell leukemia (ATL) and identification of a Single Nucleotide polymorphism in TET2 region predisposing to ATL development
}

\author{
Ambroise Marçais ${ }^{1 *}$, Katia Hanssens ${ }^{2}$, Laetitia Waast ${ }^{3}$, Vahid Asnafi ${ }^{4}$, Patrice Dubreuil ${ }^{2}$, Antoine Gessain ${ }^{5}$, \\ Claudine Pique ${ }^{3}$, Olivier Hermine ${ }^{6+}$
}

From 17th International Conference on Human Retroviruses: HTLV and Related Viruses

Trois Ilets, Martinique. 18-21 June 2015

Deregulation of DNA methylation, such as inactivation of the Ten-Eleven Translocation 2 (TET2) gene by haplo-insufficiency, has been recently identified in malignant hematologic diseases. Inactivating mutations of TET2 were first described in myeloid disorders and more recently in peripheral T-cell lymphomas especially those that are harboring $\mathrm{T}$ follicular helper features like angio-immunoblastic $\mathrm{T}$ cell lymphoma. In order to determine new oncogenic pathways in Adult $\mathrm{T}$ cell leukemia/lymphoma (ATLL), we investigated the presence of TET2 coding sequence mutations and their clinical relevance in a retrospective cohort of 66 ATL patients. We identified mono allelic inactivating mutations of TET2 gene in 12 patients of 66 analyzed (18\%). Of the 51 patients with aggressive forms (acute and lymphoma), $11(22 \%)$ had TET2 mutations while only one (7\%) of the 12 patients with indolent forms had a TET2 mutation. Of the 12 mutated patients, 8 showed the same recurrent point mutation known as a Single Nucleotide polymorphism (SNP), which creates a frameshift resulting in the introduction of premature stop codon in one allele and lead to haplo-insufficiency. We have characterized this SNP and demonstrated that the mutated gene encodes for a truncated form of Tet 2 that is no longer catalytically active. We then addressed whether this mutation could predispose to ATL development by sequencing the TET2 SNP region in 50 HTLV-1 carriers

\footnotetext{
* Correspondence: ambroise.marcais@nck.aphp.fr

+ Contributed equally

'Service d'hématologie, hôpital Universitaire Necker, Université René

Descartes, Institut Imagine, Inserm, U1016, Institut Cochin, Paris, France

Full list of author information is available at the end of the article
}

from French Guyana matching the African or French Caribbean origins of the patients. We found that the percentage of the mutation in this control population was around $4 \%$, which is similar to that of the African population and is three fold less than in our ATL cohort. This finding suggests that this mutation could be a predisposal factor for developing an ATL. In conclusion, we have showed that TET2 mutations are frequently associated with ATL, notably the aggressive forms, and that a TET2 SNP may predispose to ATL development.

\section{Authors' details \\ 'Service d'hématologie, hôpital Universitaire Necker, Université René Descartes, Institut Imagine, Inserm, U1016, Institut Cochin, Paris, France. IInserm U1068, Centre de Recherche en Cancérologie de Marseille, Institut Paoli-Calmettes, Université de la Méditerranée, Marseille, France. ${ }^{3}$ Inserm, U1016, Institut Cochin, Paris, France. ${ }^{4}$ Department d'hématologie, hôpital universitaire Necker, Université René Descartes, Paris, France. ${ }^{5}$ Unité d'épidémiologie et Physiopathologie des Virus Oncogènes, Département de Virologie, CNRS, UMR 3569, Institut Pasteur, Paris, France. 'Service d'hématologie, Hôpital Universitaire Necker, Université René Descartes, Institut Imagine, Inserm, Paris, France.}

Published: 28 August 2015

\section{doi:10.1186/1742-4690-12-S1-012}

Cite this article as: Marçais et al:: Recurrent TET2 mutations in adult

T cell leukemia (ATL) and identification of a Single Nucleotide polymorphism in TET2 region predisposing to ATL development. Retrovirology 2015 12(Suppl 1):012. 